\title{
Desempenho de vacas da raça Holandesa em pastagem de coastcross ${ }^{1}$
}

\author{
Duarte Vilela ${ }^{2}$, Josiane Aparecida de Lima ${ }^{3}$, João Cesar de Resende ${ }^{2}$, Rui da Silva Verneque ${ }^{2}$ \\ ${ }^{1}$ Pesquisa parcialmente financiada com recursos do CNPq e Rações Total \\ 2 Embrapa Gado de Leite. Rua Eugênio do Nascimento, 610 - Bairro Dom Bosco - 36038-330 - Juiz de Fora - MG.
}

RESUMO - Avaliou-se o desempenho produtivo de vacas da raça Holandesa mantidas em pastagem de coastcross (Cynodon dactylon (L.) Pears) fertilizada, irrigada e suplementada com 3 ou $6 \mathrm{~kg}$ de concentrado/vaca/dia. Dados de 108 lactações coletados durante três anos consecutivos (outubro/2000 a outubro/2003) foram analisados em um delineamento de blocos ao acaso com duas repetições por tratamento, utilizando-se nove animais por área e 18 por tratamento, com lotação fixa de cinco vacas/ha. Adotou-se o sistema de pastejo em lotação rotacionada, com um dia de ocupação e 25 e 35 dias de descanso dos piquetes, nas estações chuvosa e seca, respectivamente. A pastagem foi irrigada nos meses de menor precipitação e fertilizada com adubo formulado (NPK), distribuído a lanço em seis aplicações anuais. A disponibilidade de matéria seca foi de 7.280 e $6.167 \mathrm{~kg} / \mathrm{ha}$ no início do pastejo, com resíduo pós-pastejo de 4.885 e $3.994 \mathrm{~kg} / \mathrm{ha}$, nas estações chuvosa (primavera/verão) e seca (outono/ inverno), respectivamente. Durante parte do período experimental, algumas características morfogênicas da pastagem foram avaliadas, registrando-se disponibilidade de 83,9; 125,6 e 89,5 kg de MS de lâminas foliares/ha, nas estações de primavera, verão e outono, respectivamente. As produções médias diárias de leite (corrigidas para 3,5\% de gordura) foram de 15,5 e $19,1 \mathrm{~kg} / \mathrm{vaca}$ e de 77,8 e 94,0 kg/ha, quando foram fornecidos, para cada vaca, 3 e $6 \mathrm{~kg}$ de concentrado, respectivamente. Pastagem de coastcross, quando fertilizada e manejada adequadamente, viabiliza elevadas produtividades de leite por animal e por área, podendo ser recomendada para produção de leite em pastagens.

Palavras-chave: Cynodon, escore corporal, morfogênese, manejo, produção de leite

\section{Performance of Holsteins cows on coastcross pasture}

\begin{abstract}
The productive performance of Holstein cows grazing fertilized coastcross (Cynodon dactylon (L.) Pears) pasture, strategically irrigated and supplemented with either 3 or $6 \mathrm{~kg}$ of concentrate/cow/day, was evaluated in this trial. The data were collected for three years (October/2000 to October/2003), involving 108 lactations. A completely randomized block design with two treatment replications was adopted, with nine animals per paddock. The pasture was strip grazed at a stocking rate of five cows per hectare, with rest periods of 25 and 35 days in the rainy and dry seasons, respectively. The pasture was irrigated in the months of lowest rainfall and fertilized with NPK broadcast at six applications/year. The pre-grazing pasture masses were $7,280 \mathrm{~kg} / \mathrm{ha}$ and $6,167 \mathrm{~kg} / \mathrm{ha}$ with post-grazing residuals of 4,885 kg/ha and 3,994 kg/ha, in the rainy (Spring/Summer) and dry (Fall/Winter) seasons, respectively. During part of the experimental period, a few morphogenic characteristics of the pasture were evaluated. Leaf blade growth rates of $83.9,125.6$ and $89.5 \mathrm{~kg} \mathrm{DM} / \mathrm{ha} /$ day were recorded in the Spring, Summer and Fall season, respectively. The average daily milk yields were 15.5 and $19.1 \mathrm{~kg} / \mathrm{day} / \mathrm{cow}$ with $3.5 \%$ of fat and 77.80 and $94.00 \mathrm{~kg} / \mathrm{ha}$, for either 3 or $6 \mathrm{~kg}$ of concentrate/cow/day, respectively. It was concluded that fertilized coastcross pasture adequately managed enables high milk yields per cow and per hectare.
\end{abstract}

Key Words: Cynodon, body score, management, milk yield

\section{Introdução}

A pecuária brasileira passa, atualmente, por um acelerado processo de modernização e necessita se adequar à realidade tecnológica, substituindo o modelo extrativista por outro mais competitivo e, principalmente, sustentável. Neste novo modelo, a competitividade (entendida como a capacidade de gerar produto de qualidade a baixo custo), a qualidade, a eficácia, o crescimento e a sustentabilidade são atributos correlacionados e devem ser o objetivo pri- mordial da atividade leiteira. Para atingir esses objetivos, algumas estratégias básicas têm-se destacado e, entre elas, a produção de leite a pasto é uma das principais ferramentas para reduzir custos e aumentar a produtividade e eficácia, além de satisfazer às exigências do mercado, que procura qualidade de produto e sustentabilidade ambiental.

No Brasil, elevar a produtividade leiteira de forma sustentável e competitiva consiste no maior desafio para a pesquisa, uma vez que há grande demanda por informações sobre o uso de forrageiras tropicais manejadas intensivamente 
para produção de leite visando, principalmente, à redução dos custos de produção, e que a especialização da pecuária leiteira envolve o uso mais intensivo e racional de forrageiras tropicais. Nesse aspecto, vale ressaltar que a formação e o manejo de pastagens produtivas e adaptadas ao ambiente tropical com forragem suficiente para suprir as exigências nutricionais dos animais devem fazer parte da busca por eficiência, pois o desempenho de rebanhos leiteiros está intimamente associado, entre outros, ao seu manejo nutricional.

As gramíneas do gênero Cynodon, em razão das vantagens nutricionais, do potencial produtivo, da resposta à fertilização, da adaptação a diferentes ambientes e da flexibilidade de uso, vêm sendo intensivamente pesquisadas no Brasil. A Embrapa Gado de Leite tem desenvolvido pesquisas com o intuito de definir o melhor manejo para esta gramínea, considerando a produção intensiva de leite com animais de elevado potencial produtivo (Vilela et al.,1996, 2002, 2003a, b, 2004; Alvim et al., 1997, 1999; Mota et al., 2004). Os resultados têm sido promissores - taxas de lotação de 5 a 7 vacas/ha, com produções diárias de leite de até $104 \mathrm{~kg} / \mathrm{ha}-$ e permitem inferir que a produção de leite em pastagens de forma intensiva e racional é mais lucrativa que a produção em modelos exclusivamente de confinamento, conforme demonstraram Vilela et al. (1996) e Vilela \& Resende (2001).

Os modelos de produção com forrageiras do gênero Cynodon têm revelado alta capacidade para reduzir custos e aumentar os lucros da atividade (Vilela et al., 1996; Vilela \& Resende, 2001; Fontanelli et al., 2000). A redução no custo, associada ao aumento da escala de produção de leite, deve ser o caminho para obtenção de maior lucro e permanência na atividade. Nesse contexto, Alvim et al. (1999) avaliaram a aplicação de três doses de nitrogênio $(100,250$ e $300 \mathrm{~kg} / \mathrm{ha} / \mathrm{ano}$ ) em pastagens de coastcross e observaram, durante dois anos, produções individuais de leite semelhantes entre as doses de nitrogênio estudadas. Entretanto, a taxa de lotação foi inferior para menor dose de nitrogênio avaliada, verificando-se melhor produção de leite por área nas maiores doses de nitrogênio.

Realizou-se este estudo com o objetivo de avaliar o desempenho produtivo de vacas Holandesas mantidas em pastagem de coastcross fertilizada, irrigada e suplementada com concentrado.

\section{Material e Métodos}

O experimento foi conduzido na Embrapa Gado de Leite, em Coronel Pacheco, na Zona da Mata de Minas Gerais ( $21^{\circ} 33^{\prime} 22^{\prime \prime}$ de latitude sul e $43^{\circ} 6^{\prime} 15^{\prime \prime}$ ' de longitude oeste). O clima local é do tipo Cwa (mesotérmico), com verão chuvoso, inverno seco e precipitação média anual de 1.500 $\mathrm{mm}$, distribuída de forma irregular. As informações climatológicas dos últimos 40 anos (1961 a 1999)e as relativas ao período experimental (outubro/2000 a outubro/2003) são apresentadas na Figura 1.

Foram utilizadas 36 vacas da raça Holandesa, com peso vivo médio de $550 \mathrm{~kg}$ e potencial para produção de 6.000 a $6.500 \mathrm{~kg} /$ lactação mantidas em uma área de 7 ha de pastagem formada com Cynodon dactylon cv. coastcross, manejada em sistema de pastejo sob lotação rotacionada, com 5 vacas/ha. Os animais foram divididos em quatro grupos, com duas repetições por tratamento, ouseja, nove animais por unidade experimental 18 animais por tratamento. Cada grupo de vacas teve à disposição 40 piquetes de $470 \mathrm{~m}^{2}$, divididos por cerca elétrica.

O período de ocupação dos piquetes foi de um dia e o de descanso, de 35 dias na estação seca (outono/inverno) e 25 dias na estação chuvosa (primavera/verão). Os dados foram coletados durante três anos consecutivos (outubro/ 2000 a outubro/2003), totalizando 108 lactações (três anos com 36 animais por ano).

A pastagem foi fertilizada com $1.000 \mathrm{~kg} / \mathrm{ha} /$ ano da fórmula 20-05-20, distribuída a lanço em seis aplicações anuais, sempre após a saída dos animais dos piquetes. Nos meses com menor precipitação pluvial, a pastagem foi irrigada por aspersão, utilizando-se conjunto de irrigação convencional com vazão de $60 \mathrm{~m}^{3} /$ hora. O sistema constou de conjunto motobomba, uma linha principal com tubulações metálicas de quatro polegadas de diâmetro e duas linhas secundárias de três polegadas (uma de espera), compostas de 15 aspersores com vazão individual de $4,0 \mathrm{~m}^{3} /$ hora. Os aspersores permaneceram em espaçamento de $24 \times 18 \mathrm{~m}$, com tubos de subida de $1 \mathrm{~m}$ de altura, suspensos por tripés metálicos. O intervalo das irrigações foi avaliado por tensiômetros de cápsulas porosas, procurando-se manter o solo com água disponível entre 60 e $65 \%$. A quantidade de água em cada irrigação foi estabelecida por meio da fórmula:LB = $(\mathrm{cc}-\mathrm{f})$ Pr.da.10/Ef; em que: $\mathrm{LB}=$ lâmina bruta de água a ser aplicada ( $\mathrm{mm}) ; \mathrm{CC}=$ capacidade de campo(g água/g solo); $\mathrm{f}=$ teor de umidade do solo à tensão de $-6 \mathrm{a}-7 \mathrm{~atm}$. (gágua/g solo); $\mathrm{Pr}=$ profundidade efetiva do sistema radicular $(\mathrm{cm}) ; \mathrm{da}=$ densidade aparente do solo $\left(\mathrm{g}\right.$ solo $\left./ \mathrm{cm}^{3}\right) ; \mathrm{Ef}=$ eficiência do sistema de irrigação.

Foram estimadas as quantidades de forragem disponível e residual da pastagem, considerando-se a quantidade de forragem cortada antes (forragem disponível) e após o pastejo (forragem residual), a $8 \mathrm{~cm}$ do nível do solo, constante no interior de um quadrado de $1 \mathrm{~m}$ de lado, lançado ao acaso três vezes em cada piquete. Toda a vegetação existente 

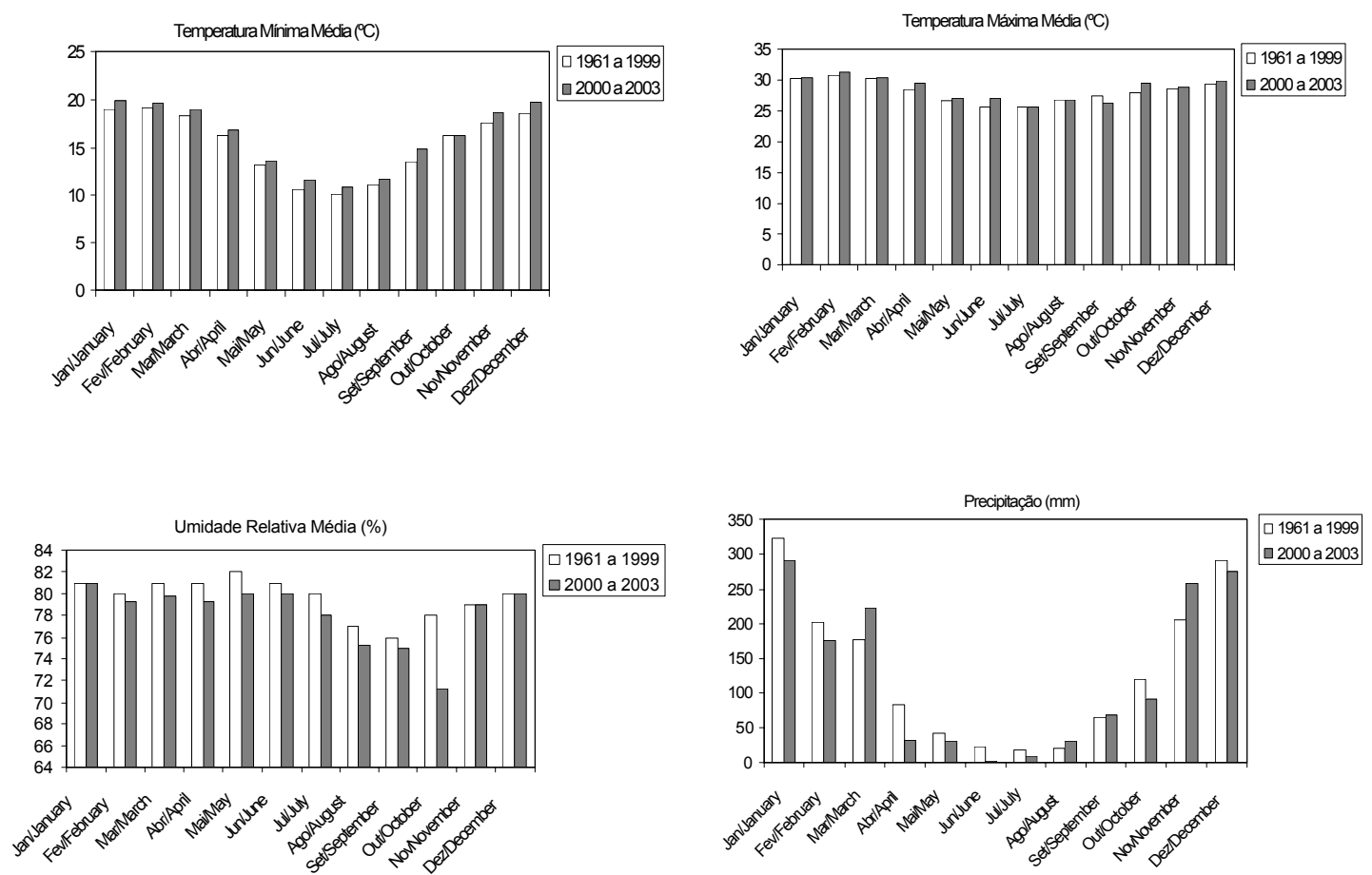

Figura 1 - Dados médios climatológicos da região no período experimental (2000 a 2003) e no período de 1961 a 1999. Figure 1 - Average climatologic data in the experimental period (2000 to 2003) and from 1961 to 1999.

abaixo de $8 \mathrm{~cm}$ foi desconsiderada. Parte do material colhido foi utilizada para estimar a qualidade da forragem (PB, FDN e digestibilidade in vitro da MS), que pode ser observada na Tabela 1. Os animais tiveram livre acesso à água e à sombra artificial (sombrite) nos piquetes.

O consumo diário de matéria seca da pastagem foi estimado pela diferença entre as quantidades disponível (acumulada no mês) e residual (após um dia de pastejo) e a taxa de lotação (5 vacas/ha).

Foram fornecidos diariamente por vaca 3,0 e $6,0 \mathrm{~kg}$ de concentrado formulado com milho integral moído (62\%), soja integral tostada (35\%), mistura mineral (2\%) e calcário calcítico (1\%), com a seguinte composição na matéria seca: $19,5 \%$ de $\mathrm{PB}, 9,3 \%$ de proteína degradável no rúmen e $86 \%$ de NDT. O concentrado foi fornecido durante as ordenhas, realizadas duas vezes ao dia $(7$ e $15 \mathrm{~h})$. Concluídas as ordenhas, as vacas eram novamente conduzidas aos piquetes. Na estação seca (maio a setembro), quando a disponibilidade de forragem estava abaixo de $4.000 \mathrm{~kg}$ de $\mathrm{MS} / \mathrm{ha}$, a pastagem foi suplementada com silagem de milho (33\% de MS) na proporção diária de $17 \mathrm{~kg}$ por vaca. A suplementação foi necessária somente no último ano de avaliação (2002/2003). A cada 15 dias, ao longo de todo o ciclo de produção, as vacas foram pesadas e submetidas a avaliações, por meio de observações visuais e táteis.
Tabela 1 - Teores médios de MS, PB, FDN e DIVMS da pastagem de coastcross (médias de três anos de avaliação)

Table 1 - Average contents of DM, CP, NDF and IVDMD of the coast cross pasture (means of three years of evaluation)

\begin{tabular}{lcccc}
\hline $\begin{array}{l}\text { Estação } \\
\text { Season }\end{array}$ & $\begin{array}{c}\text { MS } \\
D M\end{array}$ & $\begin{array}{r}\text { PB } \\
C P\end{array}$ & $\begin{array}{r}\text { FDN } \\
N D F\end{array}$ & $\begin{array}{r}\text { DIVMS } \\
\text { IVDMD }\end{array}$ \\
\hline & \multicolumn{4}{c}{$\begin{array}{c}(\% \mathrm{MS}) \\
(\% D M)\end{array}$} \\
\hline $\begin{array}{l}\text { Outono/inverno (período seco) } \\
\text { Fall/Winter (dry period) }\end{array}$ & 25,5 & 16,0 & 63,3 & 65,4 \\
$\begin{array}{l}\text { Primavera/verão (período chuvoso) } \\
\text { Spring/Summer (rainy period) }\end{array}$ & 24,0 & 18,0 & 65,8 & 65,8 \\
\hline
\end{tabular}

Atribuíram-se notas que variaram de 1 a 5:1 = muito magra; $2=$ magra $; 3=$ regular; $4=$ gorda $;$ e $5=$ muito gorda .

A produção de leite foi registrada diariamente e o critério para secagem das vacas foi 60 dias antes do parto ou quando a produção diária foi inferior a $4 \mathrm{~kg}$ por vaca. A produção de leite foi corrigida para 3,5\% de gordura (PLC) por meio da equação citada por Skalan et al. (1992): $\mathrm{PLC}=(0,432+0,1625 \times \mathrm{G}) \times$ quantidade $(\mathrm{kg})$ de leite, em que $\mathrm{G}$ é o percentual de gordura do leite.

A produção foi analisada segundo delineamento em blocos casualizados, com duas repetições e duas quantidades de concentrado (3,0 e $6,0 \mathrm{~kg} / \mathrm{vaca} / \mathrm{dia})$, utilizando-se a época de parição como critério para formação dos blocos. 


\section{Resultados e Discussão}

Nos períodos de outubro a novembro de 2000 (primavera), fevereiro a março de 2001 (verão) e maio a junho de 2001 (outono), foram avaliadas algumas características da pastagem, observando-se taxas de acúmulo diário de MS de lâminas foliares de 83,9; 125,6; e 89,5 kg/ha. Mesmo considerando a menor disponibilidade de MS registrada na primavera $(83,9 \mathrm{~kg}$ de MS/ha/dia), foi possível alcançar disponibilidade de $16,78 \mathrm{~kg} / \mathrm{vaca} / \mathrm{dia}(83,9 \mathrm{~kg}$ de MS/ha por 5 vacas/ha/dia). Esse valor refere-se apenas às lâminas foliares, pois, durante o pastejo, além de folhas, os animais ingerem também hastes verdes e tenras.

Na Tabela 2 são apresentadas as estimativas de matéria seca disponível e residual, o consumo de matéria seca proveniente da pastagem e a estimativa de consumo de matéria seca, quando fornecidos 3 ou $6 \mathrm{~kg}$ de concentrado para as vacas.

A diferença na disponibilidade de MS $(1.113 \mathrm{~kg})$ entre as estações pode ser explicada pela adubação e irrigação, que viabilizaram disponibilidade de MS na estação seca de $84,7 \%$ da alcançada na estação das chuvas, ocasionando uma diferença de resíduo pós-pastejo de $891 \mathrm{~kg} / \mathrm{ha}$ entre ambas as estações. Salienta-se que, no período seco, o menor valor médio para resíduo pós-pastejo foi registrado em agosto (2.524 kg de MS/ha).

A diferença no consumo de MS proveniente da pastagem entre as estações avaliadas (1,46 kg de MS/vaca) foi, certamente, proporcionada pela fertilização e irrigação, que estimularam a rebrota das plantas, mantendo a qualidade da forragem ao passar da estação seca para a de chuvas (Tabela 1). Além disso, a temperatura não atingiu valores excessivamente baixos na época seca (Figura 1), podendo ter contribuído para que o consumo de forragem não alterasse demasiadamente entre os dois períodos.

O consumo total de MS (pastagem, concentrado e silagem de milho) manteve-se, respectivamente, em torno de 3,3 e $3,8 \%$ do PV dos animais para consumos de 3 e $6 \mathrm{~kg}$ de concentrado, não havendo restrição de alimento para os animais. Segundo o NRC (1987), no caso de vacas da raça Holandesa com $550 \mathrm{~kg}$ de $\mathrm{PV}$ e produção diária de leite de 15 a $20 \mathrm{~kg}$, espera-se consumo diário de MS de 15,5 a 19,7 kg/ animal, confirmando que a produção de leite obtida neste estudo não foi limitada pelo consumo de MS, tampouco pela qualidade da forragem (Tabela 1).

As produções de leite por animal em diferentes períodos de avaliação e as médias referentes ao período total são apresentadas na Tabela 3.

Não houve diferença $(\mathrm{P}>0,01)$ no teor de gordura do leite entre as duas quantidades de concentrado $(3,61 \mathrm{e} 3,54 \%)$. As médias gerais ( 0 a 330 dias) da produção corrigida para 3,5\%

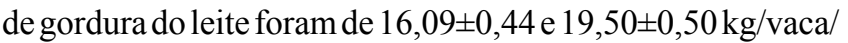
dia, respectivamente para o fornecimento de concentrado nas quantidades de 3 e $6 \mathrm{~kg} / \mathrm{vaca} / \mathrm{dia}$.

As produções médias, tanto sem correção como corrigida para 3,5\% de gordura, foram maiores $(\mathrm{P}<0,01)$, na proporção

Tabela 2 - Estimativas de MS disponível e residual ( $\mathrm{kg}$ de MS/ha), consumo diário de MS (kg/vaca) proveniente da pastagem e consumo total diário de MS (kg/vaca) por vacas da raça Holandesa em uma pastagem de coastcross durante três anos consecutivos

Table 2 - Estimates of available and residual dry matter ( $\mathrm{kg}$ of DM/ha), daily dry matter intake ( $\mathrm{kg} / \mathrm{cow}$ ) of the pasture and total daily dry matter intake (kg/cow) by Holstein cows on coastcross pasture during three years

\begin{tabular}{|c|c|c|}
\hline & \multicolumn{2}{|c|}{$\begin{array}{l}\text { Pasto } \\
\text { Pasture }^{1}\end{array}$} \\
\hline & $\begin{array}{l}\text { Estação chuvosa } \\
\text { Rainy season }\end{array}$ & $\begin{array}{c}\text { Estação seca } \\
\text { Dry season }\end{array}$ \\
\hline $\begin{array}{l}\text { MS disponível }(\mathrm{kg} / \mathrm{ha}) \\
\text { Available } D M(\mathrm{~kg} / \mathrm{ha})\end{array}$ & 7.280 & 6.167 \\
\hline $\begin{array}{l}\text { MS residual }(\mathrm{kg} / \mathrm{ha}) \\
\text { Residual } D M(\mathrm{~kg} / \mathrm{ha})\end{array}$ & 4.885 & 3.994 \\
\hline $\begin{array}{l}\text { Consumo MS da pastagem }(\mathrm{kg} / \mathrm{vaca} / \mathrm{dia}) \\
\text { DM intake of the pasture }(\mathrm{kg} / \mathrm{cow} / \text { day })\end{array}$ & 15,96 & 14,50 \\
\hline
\end{tabular}

\begin{tabular}{|c|c|c|c|c|}
\hline & \multicolumn{4}{|c|}{$\begin{array}{c}\mathrm{kg} \text { de concentrado/vaca/dia }{ }^{2} \\
k g \text { of concentrate/cow/day } y^{2}\end{array}$} \\
\hline & 3 & 6 & 3 & 6 \\
\hline Consumo total de MS (pastagem + concentrado) & 18,72 & 21,48 & 17,26 & 20,00 \\
\hline Total DM intake (pasture + concentrate) & & & & \\
\hline $\begin{array}{l}\text { Consumo total de MS (\% PV) } \\
\text { Total DM intake }(\% B W)\end{array}$ & 3,4 & 3,9 & 3,1 & $3,6^{1}$ \\
\hline
\end{tabular}

1 Valores médios de amostragens realizadas mensalmente em cada estação.

2 Concentrado com $92 \%$ de matéria seca.

${ }^{1}$ Means of samplings performed monthly, in each season.

${ }^{2}$ Concentrate with $92 \%$ of dry matter. 
Tabela 3 - Produção de leite nos três períodos de avaliação e produção total em vacas da raça Holandesa mantidas em pastagem de coastcross, recebendo diariamente 3 ou $6 \mathrm{~kg}$ de concentrado (média de três anos consecutivos)

Table 3 - $\quad$ Milk yield of Holstein cows kept on coast-cross pastures, feeding either 3 or $6 \mathrm{~kg}$ of concentrate/cow/day (mean of three years on end)

\begin{tabular}{|c|c|c|c|c|}
\hline \multirow[b]{2}{*}{$\begin{array}{l}\text { Nível de concentrado(kg/vaca/dia) } \\
\text { Concentrate level ( } \mathrm{kg} / \text { cow/day) }\end{array}$} & \multicolumn{4}{|c|}{$\begin{array}{c}\text { Produção de leite }(\mathrm{kg} / \mathrm{vaca} / \mathrm{dia}) \\
\text { Milk yield }(\mathrm{kg} / \text { cow/day })\end{array}$} \\
\hline & 0-100 (Dias) & $101-200$ (Dias) & $201-330$ (Dias) & $0-330$ (Dias) \\
\hline 3 & $19,07 \mathrm{~B} \pm 0,60$ & $15,50 \mathrm{~B} \pm 0,49$ & $11,99 \mathrm{~B} \pm 0,53$ & $15,54 \mathrm{~B} \pm 0,38$ \\
\hline 6 & $22,27 \mathrm{~A} \pm 0,85$ & $19,20 \mathrm{~A} \pm 0,64$ & $16,25 \mathrm{~A} \pm 0,63$ & $19,15 \mathrm{~A} \pm 0,45$ \\
\hline Média & $20,62 \pm 0,54$ & $17,36 \pm 0,44$ & $14,16 \pm 0,46$ & $17,07 \pm 0,23$ \\
\hline \multicolumn{5}{|l|}{ Mean } \\
\hline $\mathrm{CV}$ & & & & 22,89 \\
\hline
\end{tabular}

${ }^{1}$ Médias seguidas de letras diferentes, na coluna, diferem $(P<0,01)$ pelo teste SNK

${ }^{1}$ Mean followed by different letters in the column differ $(P<0.01)$ by SNK test.

de $6 \mathrm{~kg}$ de concentrado, independentemente do período avaliado. As vacas alimentadas com $6 \mathrm{~kg}$ de concentrado produziram, em média, $3,61 \mathrm{~kg}$ de leite/dia a mais que aquelas que receberam $3 \mathrm{~kg} / \mathrm{vaca} / \mathrm{dia}$. Entre as quantidades de concentrado avaliadas, cada quilo adicional estimulou produção de, aproximadamente, $1,2 \mathrm{~kg}$ de leite, provavelmente ocasionada pelo maior consumo de concentrado, que permitiu substituição parcial do consumo de matéria seca proveniente da pastagem. Neste caso, a maior produção das vacas que receberam $6 \mathrm{~kg}$ de concentrado foi reflexo da qualidade da dieta, independentemente do período avaliado, pois, nos primeiros 100 dias, registraram-se produções de 19,0 e 22,2 kg de leite/vaca/dia (Tabela 3 ) para 3 ou $6 \mathrm{~kg}$ de concentrado/vaca/dia. Segundo Holmes \& Wilson (1990), cada unidade de MS ingerida via concentrado estimula redução de 0,5 a 0,8 unidades no consumo de MS proveniente do volumoso.

$\mathrm{Na}$ avaliação realizada durante duas lactações sucessivas de vacas Holandesas mantidas em uma pastagem de coastcross, Vilela et al. (2004) concluíram que o fornecimento de concentrado proporcionou aumento médio de $1,0 \mathrm{~kg}$ de leite por quilo extra de concentrado fornecido. De acordo com os autores, pelos custos relativos, essa substituição seria economicamente viável somente se o preço do leite fosse igual ou superior ao do concentrado, considerando-se que a eficiência reprodutiva dos animais não foi afetada. Davidson (1990) ressalta que a decisão por usar ou não concentrados está relacionada ao preço, uma vez que a margem líquida da atividade cresce à medida que o preço do concentrado diminui e que a produção de leite aumenta.

A participação do concentrado na dieta de vacas em lactação assume maior ou menor importância, em razão também do potencial de produção individual. Conforme Cowan (1995), em sistemas com produtividades superiores a $4.500 \mathrm{~kg} / \mathrm{vaca} / \mathrm{lactação,} \mathrm{é} \mathrm{fundamental} \mathrm{a} \mathrm{suplementação}$ com concentrado. No entanto, é necessário considerar que o nível e o tipo de proteína do concentrado também afetam diretamente os custos de produção.

A persistência na lactação foi maior nos animais alimentados com $6 \mathrm{~kg}$ de concentrado por vaca/dia (-0,27 e - 0,35 $\mathrm{kg}$ de leite/vaca/dia). Alvim et al. (1997) também constataram maior persistência na lactação de vacas que receberam maior quantidade de concentrado durante o terço inicial da lactação.

Geralmente, a composição química da pastagem fertilizada apresenta o desequilíbrio na relação energia/proteína, podendo provocar concentração excessiva de proteína fermentada no rúmen. Neste caso, é necessário neutralizar o excesso de nitrogênio amoniacal presente no rúmen, por meio da suplementação estratégica com concentrados específicos. Neste estudo, como foi utilizado concentrado com maior conteúdo de energia e de baixa degradação da proteína no rúmen, proporcionada pela soja integral tostada, esse problema provavelmente não ocorreu.

As produções de leite por área foram de 77,85 e $94,00 \mathrm{~kg} /$ ha/dia para as proporções de 3 e $6 \mathrm{~kg}$ de concentrado/vaca/dia, respectivamente. Alvim et al. (1997), nas mesmas condições deste estudo, utilizando $380 \mathrm{~kg} / \mathrm{ha}$ de nitrogênio e $304 \mathrm{~kg} / \mathrm{ha}$ de potássio, fracionados em dez aplicações em cobertura, relataram produção média anual de leite próxima de $37 \mathrm{mil}$ $\mathrm{kg} / \mathrm{ha}$, com taxa de lotação de 5,1 vacas/ha. A fertilização e a irrigação viabilizam maior produção de forragem de melhor qualidade, assegurando elevadas produções de leite por área e por animal, que pode ser otimizada com a suplementação com concentrados.

O fornecimento de $6 \mathrm{~kg}$ de concentrado possibilitou produção média de 19,1 kg de leite/vaca/dia, enquanto o de $3 \mathrm{~kg}$ promoveu produção de $15,5 \mathrm{~kg}$ de leite/vaca/dia, mantendo-se lotação de 5,0 vacas/ha. Vilela et al. (1996), ao avaliarem o desempenho de vacas Holandesas em confinamento e em pastagem de coastcross sob lotação média de 5,8 vacas/ha/dia suplementada com $3 \mathrm{~kg}$ de concentrado, 
registraram produções diárias individuais de 20,6 (confinamento) e de $16,6 \mathrm{~kg}$ (pastagem). Os autores concluíram que, embora a receita proveniente do leite produzido no sistema a pasto tenha sido inferior àquela obtida pelo sistema de confinamento, a margem bruta foi $32 \%$ superior, evidenciando a viabilidade e a superioridade econômica da produção de leite a pasto em relação ao sistema de confinamento.

O potencial da pastagem de Cynodon na produção de leite de vacas Holandesas foi avaliado também por Vilela et al. (1996, 2002, 2003, 2004) e Alvim et al. (1997, 1999), que relataram produções de até $104 \mathrm{~kg}$ de leite por ha, com taxa de lotação de 7,3 vacas/ha e produções de leite individuais de 17 a $20 \mathrm{~kg} / \mathrm{dia}$. As produções médias diárias encontradas neste estudo (15,5 e 19,1 kg/vaca e 77,8 e 94,0 kg/ha), com lotação fixa de 5 vacas/ha, corroboram as reportadas por esses autores. As pequenas variações na produção por área e na taxa de lotação podem ser explicadas pelo fato de a quantidade de nitrogênio aplicada $(200 \mathrm{~kg} / \mathrm{ha})$ ter sido menor que a utilizada nos estudos supracitados $(360 \mathrm{~kg} / \mathrm{ha} /$ ano). As variações na produção de leite por animal, no entanto, estão relacionadas a utilização dos mesmos animais experimentais durante três lactações sucessivas, enquanto, nos estudos anteriores, houve reposição de animais ao término de cada experimento.

Em sistemas de produção a pasto com animais de maior potencial produtivo, é importante a suplementação concentrada para que o potencial dos animais seja manifestado. Alvim et al. (1997, 1999) e Mota et al. (2004), ao estudarem estratégias de fornecimento de concentrado, concluíram que, ao dobrar a quantidade de concentrado, foi possível aumentar a lotação da pastagem em $50 \%$ e reduzir em $11 \%$ o custo operacional relativo à pastagem.

Não houve diferença $(\mathrm{P}>0,01)$ na produção de leite entre anos (2000 a 2003) ou entre as estações do ano $(\mathrm{P}>0,01)$. A estabilidade na qualidade da pastagem entre anos e ao longo dos anos avaliados contribuiu positivamente para esses resultados, possivelmente em razão do manejo utilizado, com fertilizações regulares ao longo do ano, distribuídas em seis aplicações e facilitadas pelo uso da irrigação.

Nenhuma diferença $(\mathrm{P}>0,01)$ foi observada no escore corporal dos animais entre as duas quantidades de concentrado. Todavia, segundo Ferguson et al. (1994), tanto o excesso como o baixo peso das vacas ao parto provocam problemas metabólicos, redução da produção, menores taxas de concepção e dificuldades no momento da parição. Edmonson et al. (1989) observaram que vacas muito gordas são mais propensas à cetose, pois consomem menos alimentos logo após o parto e mobilizam reservas corporais.
De acordo com Ferguson et al. (1994), os valores do escore corporal devem variar conforme o estádio de produção: início da lactação $=2,50$ a 3,25; meio da lactação $=2,75$ a 3,25; e final da lactação $=3,00$ a 3,50. Os escores observados neste estudo enquadram-se no intervalo sugerido para o início da lactação, porém, estão abaixo dos valores sugeridos para o meio e o final da lactação. Entretanto, considerando-se que as vacas mobilizam reservas corporais e perdem peso para suprir o balanço energético negativo, pode-se inferir que o consumo de nutrientes foi suficiente para atender às exigências necessárias para mantença, produção e reprodução.

\section{Conclusões}

Pastagem de coastcross, quando adequadamente manejada, fertilizada e irrigada, apresenta boa disponibilidade de forragem, suficiente para suprir as exigências nutricionais de vacas Holandesas em plena produção. Para atingir produções acima de $15 \mathrm{~kg}$ de leite/vaca/dia e taxas de lotação de 5 vacas/ha/dia, é necessário suplementar a dieta dos animais com concentrado.

\section{Literatura Citada}

ALVIM, M.J.; VILELA, D.; LOPES, R.S. Efeito de dois níveis de concentrado sobre a produção de leite de vacas da raça Holandesa em pastagem de coast-cross. Revista Brasileira de Zootecnia, v.26, n.5, p.967-975, 1997.

ALVIM, M.J.; VERNEQUE, R.S.; VILELA, D. et al. Estratégia de fornecimento de concentrado para vacas da raça Holandesa em pastagem de coastcross. Pesquisa Agropecuária Brasileira, v.34, n.9, p.1711-1720, 1999.

COWAN, R.T. Milk production from grazing systems in northern Australia. In: SIMPÓSIO INTERNACIONAL SOBRE O FUTURO DOS SISTEMAS DE PRODUÇÃO DE LEITE NO BRASIL, 1995, Juiz de Fora. Anais... Juiz de Fora: EMBRAPACNPGL, 1995, p.41-54.

DAVIDSON, T.M. The milk production potential of forageconcentrate systems in Queensland. In: HIGH PRODUCTION PER COW SEMINAR, 1990, Sidney. Proceedings... Sidney: Queensland Departament of Primary Industries, 1990. p.1-13.

EDMONSON, A.J.; LEAN, I.J.; WEAVER, L.D. et al. A body condition scoring chat Holstein dairy cows. Journal of Dairy Science, v.72, n.1, p.68-78, 1989.

FERGUSON, J.D.; BYERS, D.; FERRY, J. et al. Round table discussion: body condition of lactating cows. Agriculture Practice, v. 15, n.14, p.17-21, 1994.

FONTANELLI, R.S.; SOLLENBERGER, L.E.; STAPLES, C.R. Dairy cow performance pasture-based feeding systems and in confinement. Gainesville: University of Florida, 2000. 23p.

HOlMES, C.W.; WILSON, G.F. Produção de leite a pasto. Campinas: Instituto Campineiro de Ensino Agrícola, 1990. 708p.

MOTA, M.F.; SANTOS, G.T.; VILELA, D. et al. Desempenho de vacas da raça Holandesa a pasto. In: REUNIÃO ANUAL DA SOCIEDADE BRASILEIRA DE ZOOTECNIA, 41., 2004, Campo Grande. Anais... Campo Grande: SBZ, 2004. CD-ROM.

NATIONAL RESEARCH COUNCIL - NRC. Predicting feed intake of food producing animals. Washington, D.C.: National Academy Press, 1987. 85p. 
SKALAN, D.; ASHKENAZI, R.; BRAUN, A. et al. Fatty acids calcium soaps of fatty acids, and cottonseeds fed to high yielding cows. Journal of Dairy Science, v.75, p.2463-2472, 1992.

VIlelA, D.; AlViM, M. J.; CAMPOS, O. F.; RESENDE, J. C. Produção de leite de vacas Holandesas em confinamento ou em pastagem de coast-cross. Revista da Sociedade Brasileira de Zootecnia, v.25, n.6, p.1228-1244, 1996.

VILELA, D.; MATOS, L.L.; ALVIM, M.J. et al. Utilização de soja integral tostada na dieta de vacas em lactação, em pastagem de coast-cross (Cynodon dactylon L. Pers.). Revista Brasileira de Zootecnia, v.32, n.5, p.1243-1249, 2003 b.

VILELA, D.; MATOS, L.L.; ALVIM, M J. et al. Utilização de gordura protegida durante o terço inicial da lactação de vacas leiteiras, em pastagem de coast-cross. Pesquisa Agropecuária Brasileira, v.37, n.10, p.1503-1509, 2002.

VILELA, D.; RESENDE, J.C. Custo de produção de leite segundo o sistema de produção a pasto ou confinado. In: SOMPÓSIO SOBRE PRODUÇÃO E UTILIZAÇÃO DE FORRAGENS CONSERVADAS, 2001, Maringá. Anais... Maringá: Universidade Estadual de Maringá, 2001. p.218-241.
VILELA, D.; SALES, E.C.J.; ELYAS, A.C.W. et al. Efeito da suplementação concentrada na quantidade, qualidade e economia do leite produzido por vacas Holandesas em pastagem de Cynodon. In: REUNIÃO ANUAL DA SOCIEDADE BRASILEIRA DE ZOOTECNIA, 40., 2003. Santa Maria. Anais... Santa Maria: SBZ, 2003a. CD-ROM.

VILELA, D.; FERREIRA, A.M. ; SALES, E.C.J.; RESENDE, J. C.; VERNEQUE, R. S. Efeito da suplementação concentrada no intervalo parto- primeiro cio detectado pelos métodos visual e da dosagem de progesterona em vacas holandesas manejadas em pastagem de Cynodon em lotação rotacionada. In: REUNIÃO ANUAL DA SOCIEDADE BRASILEIRA DE ZOOTECNIA, 41., 2004, Campo Grande. Anais... Campo Grande: SBZ, 2004. CD-ROM. 